\title{
Simulasi Virtual Laboratorium untuk Pengajaran Jaringan Komputer
}

\author{
Aditya Prapanca ${ }^{1}$ I Made Suartana ${ }^{2}$ \\ 1,2 Teknik Informatika, Universitas Negeri Surabaya \\ 1adityaprapanca@unesa.ac.id \\ 2madesuartana@unesa.ac.id
}

\begin{abstract}
Abstrak- Jaringan komputer merupakan komponen infrastruktur penting di dunia saat ini. Masyarakat semakin bergantung pada komunikasi, informasi, dan layanan yang disampaikan melalui jaringan komputer terutama internet. Pada bidang pendidikan terutama bidang informatika jaringan komputer merupakan salah satu mata kuliah dasar. Konsep dan praktik Jaringan Komputer ini sangat penting karena teknologi internet didominasi oleh satu set protokol yaitu TCP/IP. Tanpa pengetahuan konsep TCP/IP, siswa akan sulit menerapkan konsep jaringan dalam industri. Pembelajaran jaringan komputer seringkali hanya dengan konsep teoritis, yang diilustrasikan dengan contoh-contoh dari jaringan yang nyata, dengan praktek nyata yang terbatas. Sedangkan tanpa pengalaman belajar praktis tentang jaringan komputer akan sulit memahami implementasi dari jaringan komputer. Karena kebutuhan untuk pengetahuan/pengalaman praktis tentang protokol dan sistem jaringan, diperlukan suatu laboratorium sebagai penunjang. Dalam pembelajaran jaringan komputer, pengalaman belajar praktis (hand-on) dapat menjadi suatu masalah atau tantangan karena keterbatasan sarana dan prasarana. Untuk memenuhi kemampuan belajar praktis sarana prasarana jaringan yang dibutuhkan cukup banyak dan membutuhkan biaya yang tidak sedikit, bagi beberapa kalangan pemenuhan sarana dan prasarana masih menjadi suatu masalah. Laboratorium khususnya laboratorium jaringan komputer pada umumnya terdiri dari hardware (perangkat jaringan) untuk latihan, atau perangkat lunak untuk mensimulasikan jaringan. Dengan pendekatan kedua bisa dijadikan solusi untuk mengatasi permasalahan kurangnya fasilitas atau perangkat jaringan nyata. Laboratorium virtual menjadi pilihan solusi untuk mengatasi keterbatasan dan memberikan pengalaman belajar kepada siswa.
\end{abstract}

Kata Kunci- Jaringan Komputer, virtualisasi, Simulasi, GNS3, Virtual Laboratorium.

\section{Pendahuluan}

Jaringan komputer merupakan komponen infrastruktur penting di dunia saat ini. Masyarakat semakin bergantung pada komunikasi, informasi, dan layanan yang disampaikan melalui jaringan komputer terutama internet. Pentingnya jaringan komputer tercermin dalam kurikulum pada bidang pendidikan seperti ilmu komputer dan teknik komputer/informatika. Pada kurikulum bidang informatika, jaringan komputer merupakan salah satu mata kuliah dasar pada bidang tersebut. Pembelajaran jaringan komputer mencakup prinsip-prinsip desain jaringan dan operasi seperti: protokol yang mendefinisikan interaksi pada link, node jaringan, dan aplikasi end-sistem, perangkat jaringan, pengaturan dan fungsinya, pengalamatan dan algoritma yang memungkinkan pemilihan jalur terpendek pada routing, dan penjadwalan paket, dan aplikasi jaringan yang menjadi interface jaringan dengan sistem lain yang memanfaatkan jaringan komputer. Pada proses pembelajaran jaringan, umumnya berupa penjelasan konsep teoritis yang diilustrasikan dengan contoh-contoh dari jaringan yang nyata. Sedangkan pengetahuan praktis masih terbatas dikarenakan keterbatasan sarana dan prasarana. Padaha aspek pengetahuan praktis sangat penting karena teknologi internet didominasi oleh satu set protocol yaitu, TCP/IP. Tanpa pengetahuan konsep dan teknis TCP/IP, siswa akan sulit menerapkan konsep jaringan dalam industri atau bahkan dalam penelitian jaringan.

Karena kebutuhan untuk pengetahuan/pengalaman praktis tentang protokol dan sistem jaringan, diperlukan suatu laboratorium penunjang. Dalam pembelajaran jaringan komputer, pengalaman belajar praktis(hand-on) dapat menjadi suatu masalah atau tantangan. Masalah meliputi: kurangnya dana untuk membangun dan memelihara perangkat keras dan perangkat lunak jaringan dalam jumlah yang cukup sehingga setiap siswa dapat memiliki akses yang sama, kurangnya ruang fisik, baik ruang ber-AC untuk server, dan untuk perangkat keras yang digunakan langsung oleh siswa, kurangnya lingkungan jaringan yang aman dan dapat diandalkan untuk melindungi layanan lain yang disediakan pada jaringan, dan laboratorium yang sering dibutuhkan untuk beberapa mata pelajaran dengan beragam konfigurasi software dan hardware.

Laboratorium khususnya laboratorium jaringan komputer pada umumnya terdiri dari hardware (perangkat jaringan) untuk latihan, atau perangkat lunak untuk mensimulasikan jaringan. Dengan pendekatan kedua bisa dijadikan solusi untuk mengatasi permasalahan kurangnya fasilitas atau perangkat jaringan nyata. Laboratorium virtual menjadi pilihan solusi untuk mengatasi keterbatasan dan memberikan pengalaman belajar kepada siswa[3].

Dalam penelitian ini menggunakan pendekatan pengalaman belajar praktis (hand-on) pada praktikum kuliah jaringan komputer dengan menggunakan lingkungan belajar virtual. Lingkungan belajar virtual dikembangkan dengan menggunakan teknologi virtualisasi dan menggunakan simulator GNS3.

\section{KAJIAN PUSTAKA}

\section{A. Teknologi Virtualisasi}

Menurut kamus besar bahasa Indonesia, virtual berarti (secara) nyata, sedangkan akhiran -isasi menyatakan makna melakukan, proses, usaha, atau kegiatan. Berarti virtualisasi adalah proses menyatakan atau membuat sesuatu 
menjadi nyata. Sedangkan dalam ilmu komputer, virtualisasi bisa diartikan sebagai pembuatan suatu bentuk simulasi dari sesuatu yang asalnya bersifat fisik, misalnya sistem operasi, perangkat penyimpanan data atau sumber daya jaringan. Definisi lainnya adalah "sebuah teknik untuk menyembunyikan karakteristik fisik dari sumber daya komputer dari bagaimana cara sistem lain, aplikasi atau pengguna berinteraksi dengan sumber daya tersebut. Hal ini termasuk membuat sebuah sumber daya tunggal (seperti server, sebuah sistem operasi, sebuah aplikasi, atau peralatan penyimpanan terlihat berfungsi sebagai beberapa sumber daya logikal; atau dapat juga termasuk definisi untuk membuat beberapa sumber daya fisik (seperti beberapa peralatan penyimpanan atau server) terlihat sebagai satu sumber daya logikal [1].

Dalam ilmu komputer, ada dua jenis virtualisasi yaitu virtualisasi penuh dan virtualisasi paruh. Virtualisasi penuh maksudnya mensimulasikan secara lengkaphal-hal yang mendasari suatu perangkat, sedangkan virtualisasi paruh hanya mensimulasikan beberapa hal dari perangkat tersebut.Virtualisasi paruh lebih mudah dijalankan daripaada virtualisasi penuh, akan tetapi virtualisasi paruh memiliki kekurangan dalam hal compatibility/kesesuaian.Virtualisasi dapat diimplementasikan kedalam berbagaibentuk, antara lain:

- Network Virtualization: VLAN, Virtual IP (untclustering), Multilink

- Memory Virtualization: pooling memory dari node-node di cluster

- Grid Computing: banyak komputer = satu

- Application Virtualization: Dosemu, Wine

- Storage Virtualization: RAID, LVM

- Platform Virtualization: virtual computer [2]

\section{B. Virtual Laboratorium}

Laboratorium Virtual adalah berupa software komputer yang memiliki kemampuan untuk melakukan modeling peralatan komputer secara matematis yang disajikan melalui sebuah simulasi. Laboratorium Virtual diperlukan untuk memperkuat pemahaman konsep dalam proses pembelajaran. Laboratorium Virtual bukanlah pengganti tetapi bagian dari Laboratorium riil yang digunakan untuk melengkapi dan memperbaiki kelemahan - kelemahan yangada. Laboratorium Virtual mungkin tidak perlu komprehensif, namun pada prinsipnya adalah bentuk upaya pengintegrasikandengan tujuan:

- Memberikan alat kepada siswa untuk bekerja dalam mengimplementasikan konsep yang ada pada;

- Memberikan kesempatan kepada siswa dalam rangka memperoleh pemahaman yang lebih mendalam, bila dibandingkan dengan pengajaran konvensional atau hanya berdasarkan pada teori;

- Mendorong siswa untuk lebih mendapatkan pengaaman praktis dalam cara yang sama dengan bagaimana para ahli bekerja dalam konteks penelitiannya.
Laboratorium digital memiliki komponen sebagai berikut:

- Pemodelan adalah proses dimana kita membangun representasi dari suatu objek nyata. Modeling digunakan untuk memperbaiki kekurangan pada proses pembelajaran yang mengedepankan metode cermah dan latihan soal, karena pada prinsipnya pemodelan atau modeling digunakan dengan mengajak siswa atau peserta didik dalam mendesain secara fisik yang diperlukan dalam proses untuk menggambarkan, menjelaskan dan memprediksi sebuah fenomena

- Simulasi Merupakan program komputer yang mereproduksi fenomena alam melalui visualisasi dari sebuah model. Simulasi dapat: a.membantu siswa dalam mempelajari model fenomena alam dalam dunia nyata yang memiliki perilaku sistem kompleks. b.

membantu siswa untuk memahami dunia konseptual dari ilmu pengetahuan melalui animasi, yang dapat meningkatkan pemahaman dari konsep ilmiah yang abstrak. Bahwa pada setiap kasus ditunjukkan dengan simulasi adalah sesuatu yang produktif atau bahkan sangat produktif, karena dapat mengembangkan pemahaman konseptual siswa secara nyata)

C. GNS3

GNS3 adalah software open source yang mensimulasikan jaringan komputer. GNS3 adalah network simulator grafis tetapi sebenarnya menggunakan emulator seperti Dynamips dan Qemu untuk menciptakan perangkat yang setara dengan software atau perangkat keras. GNS3 menyediakan sebuah antar muka untuk membuat topologi jaringan yang terdiri dari perangkat jaringan seperti router, switch,serta host. Jaringan yang disimulasikan dengan menggunakan GNS3 dapat dihubungkan dengan mesin virtualeksternal dan perangkat fisik.

Komponen-komponen yang terdapat dalam GNS3 sebagai berikut:

- Dynamips: Dynamips adalah perangkat lunak yang mengemulasi router Cisco pada komputer pribadi.

- Qemu adalah emulator yang bersifat open source yang berfungsi sama seperti sebuah mesin/komputer virtual

- VPCS (Virtual PC Simulator) adalah simulator dan bukan mesin emulator seperti Qemu. Ini berjalan sebagai program Windows atau Linux dan hanya menyediakan beberapa perintah dasar pada jaringan seperti ping dan traceroute. VPCS memungkinkan untuk menambahkan host ringan untuk jaringan GNS3.

- WinPcap adalah sofware dibundel dengan GNS3 dan dibutuhkan oleh GNS3 untuk mengirim paket ke dan menerima paket dari NIC (network interface card).

- Wireshark adalah penganalisa protokol jaringan dan versi 1.10.2 dikemas dengan GNS3 0.8 .6 
memungkinkan untuk melihat ke dalam paket pada trafik jaringan komputer.

\section{METODOLOGI}

Karena kebutuhan untuk pengetahuan /pengalaman praktis tentang protokol dan sistem jaringan, diperlukan suatu laboratorium. Laboratorium khususnya laboratorium jaringan komputer pada umumnya terdiri dari hardware (perangkat jaringan) untuk latihan (hands-on), atau perangkat lunak untuk mensimulasikan jaringan. Virtual laboratorium menggunakan perangkat keras dan perangkat lunak yang ada untuk menyajikan lingkungan jaringan virtual di mana siswa aman dan dapat mempelajari dan bereksperimen dengan teknologi jaringan.

Pembelajaran jaringan komputer mencakup prinsip-prinsip desain jaringan dan operasi seperti: 1. protokol yang mendefinisikan interaksi pada link, node jaringan, dan aplikasi end-sistem, 2. Perangkat pada jaringan, pengaturan dan fungsinya pada jaringan komputer,3. Pengalamatan dan algoritma yang memungkinkan pemilihan jalur terpendek pada routing, dan penjadwalan paket, 4. Aplikasi jaringan yang menjadi interface jaringan dengan komponen lain yang memanfaatkan jaringan komputer.

Berdasarkan kebutuhan pengalaman belajar praktis untuk Kuliah Jaringan Komputer, maka dikembangkan virtual laboratorium dengan menggunakan perangkat keras dan perangkat lunak simulasi dengan menggunakan GNS3. Fitur dalam Virtual Laboratorium yang dikembangkan sebagai berikut :

- Pengenalan Lingkungan simulasi dengan GNS3

- Perancangan dan Implementasi jaringan

- Implementasi Routing Statis

- Implementasi Routing Dinamis

- Implementasi Aplikasi pada Jaringan Komputer.

\section{A. Pengenalan Lingkungan Simulasi dengan GNS3}

Tujuan dari pengembangan fitur ini adalah untuk memperkenalkan lingkungan simulasi GNS3. Sehingga pengguna dapat memanfaatkan Simulator GNS3 untuk melakukan kegiatan praktikum Jaringan Komputer berbasis Virtual Lab. Pengenalan GNS3 meliputi: pengenalan fiturfitur yang dimiliki GNS3 dan bagaimana menambahkan perangkat dan melakukan pengaturan dan uji coba dari jaringan yang sudah diimplementasikan secara virtual.

\section{B. Konfigurasi Perangkat jaringan}

Tujuan dari pengembangan fitur ini adalah untuk berkenalan dengan prinsip-prinsip desain jaringan lokal dan untuk merancang komputer area jaringan lokal. Mengimplementasikan rancangan jaringan dengan menggunakan perangkat-perangkat jaringan seperti Router Switch/Hub, Komputer serta menghubungkan masing-masing perangkat menggunakan media transmisi kabel. Merancang dan mengimplementasikan pengalamatan pada jaringan menggunakan IP addres dan Proses Subnneting.

\section{Implementasi Routing Statis}

Tujuan Pengembangan fitur Routing Statis adalah memberikan pengalaman untuk melakukan konfigurasi pada router jaringan dan menerapkan proses routing statis untuk menghubungkan segmen/subnet yang berbeda pada jaringan komputer. Selain itu proses perencanaan routing statis diharapkan dapat memberikan pengalaman untuk merancang dan mengimplementasikan proses routing pada jaringan komputer dan melakukan analisa hasi dari rancangan routing yang sudah diterapkan dengan menganalisa routing tabel dan kenvergensi jaringan.

\section{Implementasi Routing Dinamis}

Tujuan Pengembangan fitur Routing Dinamis adalah memberikan pengalaman untuk melakukan konfigurasi pada router jaringan dan menerapkan proses Routing Dinamis untuk menghubungkan segmen/subnet yang berbeda pada jaringan komputer. Protokol routing dinamis yang digunakan adalah protokol RIP dan OSPF, Selain itu proses perencanaan Routing Dinamis diharapkan dapat memberikan pengalaman untuk merancang dan mengimplementasikan proses routing pada jaringan komputer dan melakukan analisa hasi dari rancangan routing yang sudah diterapkan dengan menganalisa routing tabel dari protokol RIP dan OSPF dari segi kenvergensi jaringan.

\section{E. Implementasi Aplikasi}

Tujuan dari pengembangan fitur ini adalah agar dapat mengimplementasikan aplikasi pada layer ke 7 OSI Layer dan Layer ke 4 TCP/IP layer, yaitu layer Aplkasi. Pada Layer Aplikasi terdapat beberapa aplikasi dan protokol jaringan jaringan seperti : Web Server (dengan menggunakan Hypertext Transport Protocol/HTTP), Aplikasi File transfer (dengan menggunakan File Tranfer Protocol/FTP), Aplikasi email (dengan menggunakan Simple Mail Transfer Protocol/SMTP), Mekanisme DHCP (Dynamic Host Configuration Protocol), dan Mekanisme DNS (Domain Name Service).

\section{F. Evaluasi}

Bentuk evaluasi yang dirancang terdiri dari bagian berikut:

- Bagian pertama mengacu pada aspek fungsional dan kegunaan. Bagian ini mencakup indikator untuk mengukur: efektivitas penggunaan virtual lab, relevansi, dan aksesibilitas.

- Bagian kedua didasarkan pada aspek teknis, bagian ini menilai indikator kualitas konten, struktur dan penggunaan platform GNS3 sebagai simulator.

- Bagian ketiga membahas aspek didaktik, bagian ini memberikan informasi tentang: kapasitas motivasi (daya tarik, minat), kesesuaian sebagai pengajaran pendukung bahan untuk merealisasikan praktik laboratorium, atau 
mengajukan banding sebagai bahan untuk menggantikan praktik laboratorium sesungguhnya.

- Bagian terakhir adalah untuk komentar, berisi pendapat siswa tentang penggunaan laboratorium virtual sebagai penunjang proses pembelajaran, dan meliputi tentang masalah atau ketidaknyamanan yang mungkin timbul dari penerapannya.

Kategori peringkat yang ditetapkan untuk masing-masing item dan untuk keseluruhan penilaian adalah: Bagus: 5 poin pada skala Likert; Di atas rata-rata: 4 poin pada skala Likert, Rata-rata: 3 poin pada skala Likert; Rata-rata Bellow: 2 poin pada skala Likert, Sangat Buruk: 1 poin pada skala Likert.[4]

\section{IV.HASIL DAN PEMBAHASAN}

Virtual laboratorium menggunakan perangkat keras dan perangkat lunak yang ada untuk menyajikan lingkungan jaringan pada lingkungan virtual di mana siswa aman dan dapat mempelajari dan bereksperimen dengan teknologi jaringan. Fitur dalam Virtual Laboratorium yang dikembangakan sebagai berikut :

- Pengenalan Lingkungan simulasi dengan GNS3

- Perancangan dan Implementasi jaringan

- Implementasi Routing Statis

- Implementasi Routing Dinamis

- Implementasi Aplikasi pada Jaringan Komputer.

\section{A. Pengenalan Lingkungan simulasi dengan GNS3}

Pada fitur ini adalah penggunadiperkenalkan dengan lingkungan simulasi GNS3. Sehingga pengguna dapat memanfaatkan Simulator GNS3 untuk melakukan kegiatan praktikum Jaringan Komputer berbasis Virtual Lab. Pengenalan GNS3 meliputi: pengenalan fitur-fitur yang dimiliki GNS3 dan bagaimana menambahkan perangkat dan melakukan pengaturan dan uji coba dari jaringan yang sudah diimplementasikan secara virtual.

\section{B. Perancangan dan Implementasi jaringan}

Pada fitur ini pengguna dapat mengimplementasikan rancangan jaringan dengan menggunakan perangkat-perangkat jaringan seperti Router Switch/Hub, Komputer serta menghubungkan masing-masing perangkat menggunakan media transmisi kabel. Merancang dan Mengimplementasikan pengalamatan pada jaringan menggunakan IP address dan Proses Subnneting. Ilustrasi dari fitur ini dapat dilihat pada gambar 1.

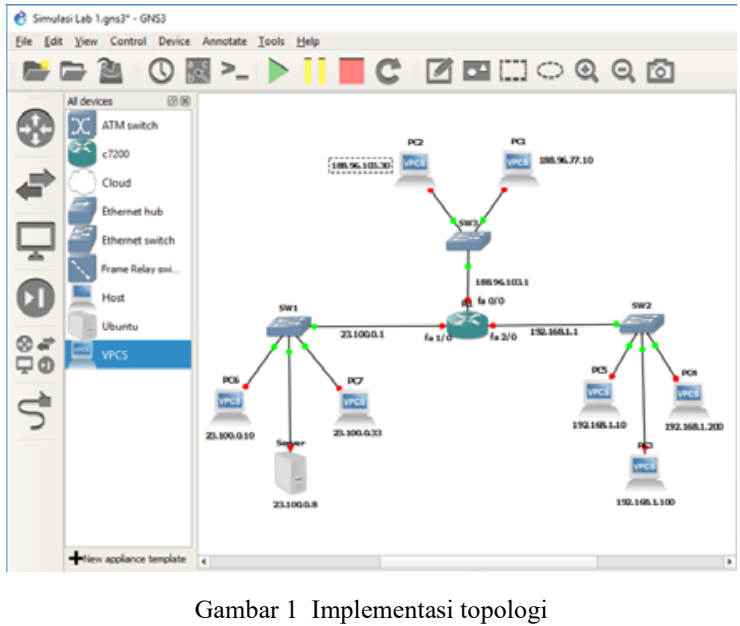

C. Implementasi Routing Statis

Pada fitur ini pengguna dapat melakukan konfigurasi routing statis pada topologi jaringan yang sudah ditentukan. Hasil dari proses ini diharapkan dapat memberikan pengalaman untuk merancang dan mengimplementasikan proses routing pada jaringan komputer dan melakukan analisa hasi dari rancangan routing yang sudah diterapkan dengan menganalisa routing tabel dan kenvergensi jaringan.

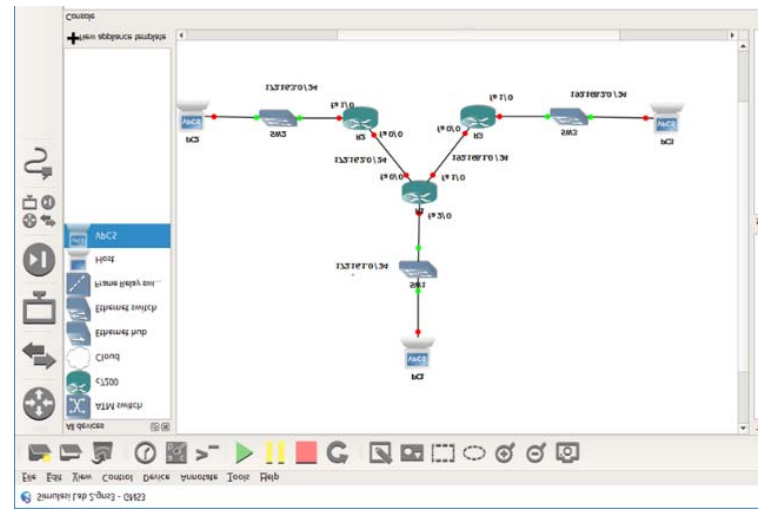

Gambar 2 Implementasi Routing statis

\section{Implementasi Routing Dinamis}

Pada fitur ini pengguna dapat melakukan konfigurasi routing dinamis dengan menggunaka protokol routing RIP dan OSPF.Hasil dari proses ini diharapkan dapat memberikan pengalaman untuk merancang dan mengimplementasikan proses routing pada jaringan komputer. Ilustrasi dari fitur ini dapat dilihat pada gambar 2 . 


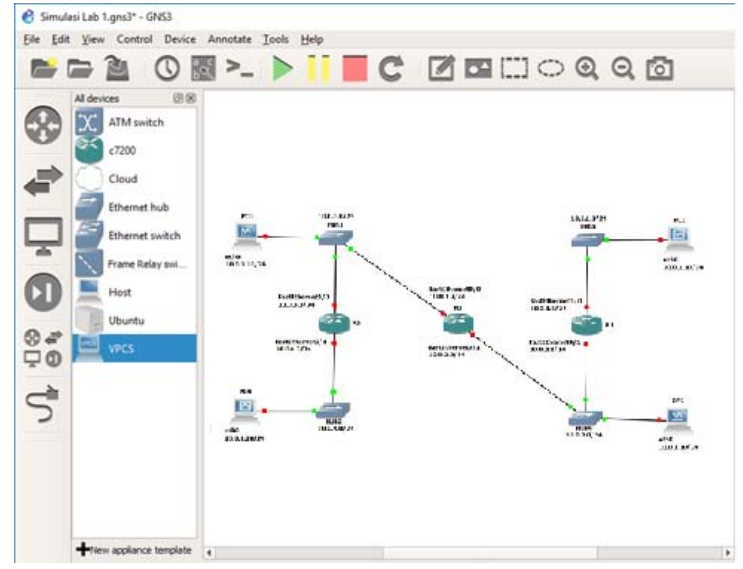

Gambar 3 Implementasi Routing Dinamis

\section{E. Implementasi Aplikasi pada Jaringan Komputer}

Gambar 4 menggambarkan desain jaringan untuk Virtual Laboratorium. Komputer siswa terhubung melalui internet ke server lab. Koneksi jaringan virtual ke internet adalah melalui *. *. *. 101. sebagai router untuk jaringan itu sendiri melalui IP Privat 192.168.100.1. Dalam Virtual Laboratorium juga terdapat mesin virtual untuk siswa. Server memiliki tiga interface(antarmuka) jaringan virtual (192.168.10. *) yang hanya berfungsi sebagai koneksi antara server fisik dan server virtual. Semua komputer virtual siswa memiliki antarmuka jaringan kedua menuju jaringan 192.168.15. *, Untuk menghubungkan mereka ke 192.168.10.1 tes server.

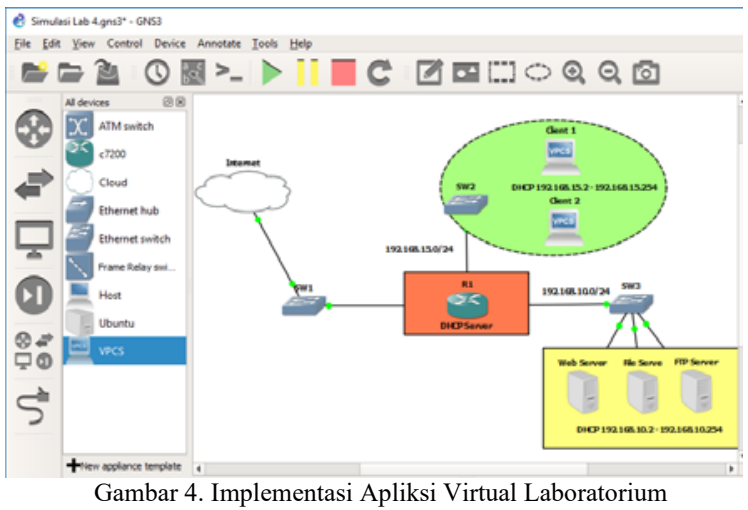

Hasil yang diperoleh dari proses uji coba dan evaluasi yang dilakukan pada sekelompok mahasiswa sebagai berikut: Pertama, penilaian aspek fungsional oleh mahasiswa dalam kelompok percontohan secara keseluruhan sangat positif. Sebagian besar aspek nilai berada pada kisaran kualitas Di atas rata-rata atau Sangat Bagus pada skala Likert. Jika kita membuat analisis yang lebih spesifik, bagian yang memiliki penilaian baik adalah instruksional dan pemodelan perangkat keras dengan menggunakan simulasi yang dinilai Bagus oleh $52,3 \%$ dan sangat bagus oleh $42,8 \%$ siswa. Item yang memiliki nilai terburuk adalah indikator yang mengukur aksesibilitas dikarenakan kompatibilitas perangkat keras atau komputer yang digunakan uji coba oleh siswa. Hal ini dapat diperbaiki di laboratorium virtual masa depan. Ilustrasi dari fitur ini dapat dilihat pada gambar 3 .

\section{KESIMPULAN}

Keterbatasan dari ketersedian perangkat nyata ternyata dapat diatasi dengan menggunakan simulasi. Walaupun 100\% tidak mewakili seperti dalam dunia nyata, namun secara prinsip keilmuan dapat dipertanggungjawabkan menggunakan program aplikasi GNS3. Software ini dapat memberikan pengalaman praktis kepada siswa dalam pembelajaran jaringan komputer.

GNS3 dapat digunakan untuk merancangan dan mengembangkan sebuah virtual laboratorium untuk memberikan pengalaman belajar praktis kepada siswa pada materi kuliah Jaringan Komputer. Siswa tinggal memilih komponen yang tersedia, atau download dahulu jika belum ada, kemudian memasangkannya di layar kerja. Cukup dengan mengklik dan mendrag mouse pada komponen yang dipilih.

Layar kerja dari GNS3 dapat digunakan sekehendak siswa dalam mengimplementasikan rancangan jaringan dengan menggunakan perangkat-perangkat jaringan seperti Router Switch/Hub, Komputer serta menghubungkan masing-masing perangkat menggunakan media transmisi kabel. Juga dapat digunakan merancang dan mengimplementasikan pengalamatan pada jaringan menggunakan IP address dan Proses Subnneting. Sehingga teknologi virtualisasi dapat terwujud dalam mensimulasikan komponen-komponen / perangkat pada jaringan komputer.

\section{REFERENSI}

[1] Hidayati Rima, Konsep Virtualisasi, ilmukomputer.com, 2007.

[2] Wolf Tilman, Assessing Student Learning in a Virtual Laboratory Environment, IEEE Transactions On Education, Vol. 53, No. 2, May 2010

[3] Zlateva Tanya, Virtual Laboratories for Learning Real World Security, Proceedings of the 12th Colloquium for Information Systems Security Education, June, 2008.Muhammad Metev \& Pardjiyo Veiko, Laser Assisted Microtechnology, 2nd ed., R. M. Osgood, Jr., Ed. Berlin, Germany: Springer-Verlag, 1998

[4] Zacharia, Z. and Roger Anderson, O., "The effects of an interactive computer-based simulation prior to performing a laboratory inquirybased experiment on students' conceptual understanding of physics", Am JPhys 71(6), 618-629 (2003). 